\title{
Validity and reliability of a questionnaire on knowledge, attitude, practice and perception (KAP2) towards food poisoning and its prevention during dining out among consumers in Terengganu
}

\author{
${ }^{1}$ Nur Afifah, M.Z., ${ }^{1, *}$ Asma', A., ${ }^{2}$ Raihana, N.I., ${ }^{2}$ Malina, O., ${ }^{2}$ Chee, H.Y., ${ }^{2}$ Misni, N., \\ ${ }^{3}$ Sukeri, S. and ${ }^{4}$ Chin, C.P.Y. \\ ${ }^{1}$ Faculty of Fisheries and Food Science, Universiti Malaysia Terengganu, 21030 Kuala Nerus, Terengganu, \\ Malaysia \\ ${ }^{2}$ Department of Medical Microbiology, Faculty of Medicine and Health Sciences, Universiti Putra Malaysia, \\ 43400 UPM Serdang, Selangor Darul Ehsan, Malaysia \\ ${ }^{3}$ Department of Community Medicine, School of Medical Sciences, Universiti Sains Malaysia, 16150 Kota \\ Bharu, Kelantan, Malaysia \\ ${ }^{4}$ Faculty of Computing and Informatics, Universiti Malaysia Sabah, 88300 Kota Kinabalu, Sabah, Malaysia
}

\begin{abstract}
Article history:
Received: 14 November 2020

Received in revised form: 19

December 2020

Accepted: 16 February 2021

Available Online: 4 July 2021

Keywords:

Questionnaire development, Validity,

Reliability,

Food poisoning and its prevention
\end{abstract}

\section{DOI:}

https://doi.org/10.26656/fr.2017.5(4).603

\section{Abstract}

Having adequate knowledge, attitude, practice, and realistic perception (KAP2) of food poisoning prevention will minimize the risk of food poisoning while dining out. However, there is no validated KAP2 questionnaire on the prevention of food poisoning during dining out, notably among consumers. Throughout the current research, a validated KAP2 questionnaire on food poisoning and prevention during dining was developed. A crosssectional pilot survey was conducted among 30 selected consumers in Kuala Nerus, Terengganu. Convenience sampling was applied to the recruitment of consumers based on inclusion and exclusion criteria. The KAP2 questionnaire comprised the knowledge section (42 questions), attitude (15 questions), practice (13 questions) and the perception (15 questions). Knowledge questions were analysed using difficulty and discrimination index, while attitude, practice, and perception were analysed by construct validity and reliability analysis. The difficulty index with less than 0.3 is considered as difficult, between $0.30-0.70$ as an acceptable value, and more than 0.70 as easy. The discrimination index below than 0.2 is considered poor, between $0.2-0.24$ as good, more than 0.35 as excellent items. The construct validity was conducted by referring to the value of Cronbach's alpha, inter-item correlation $(>0.30)$, item-total correlation $(>0.30)$, and Cronbach's alpha if item deleted. The results were found from 42 knowledge items, 29 easy items, ten acceptable items and three difficult questions. The discrimination index revealed that 25 items were poor, 11 items were excellent, three items had a good discrimination index and three items needed to be revised. Based on construct validity, five attitude's items, three practice's items and ten perception's items were removed due to inter-item correlation and item-total correlation value $<0.30$. The reliability analysis of the attitude portion was 0.848 which is a good reliability, 0.780 practice, and 0.611 perceptions to be found an acceptable value of reliability. Overall, the developed KAP2 questionnaire is a valid and reliable questionnaire that can serve as an evaluation tool for measuring knowledge, attitudes, practice and perception in the prevention of food poisoning during dining out among consumers.

\section{Introduction}

Surveys of lifestyle-related diseases have become common in community environments (Reethesh et al., 2019). The knowledge, attitude, practice, and perception (KAP2) surveys will identify gaps in the knowledge, barriers and attitudes that can influence understanding and action, as well as a formal study aimed at analysing and understanding human responses to a phenomenon, particularly in the health studies (De Pretto et al., 2015). Furthermore, Ali et al. (2018) stated that knowledge 
could influence one's attitudes and behaviours. The findings were, however, contrary to Mohd-Firdaus's previous report. Mohd. Firdaus et al. (2015) stated that a reasonable level of knowledge does not inherently become good preventive behaviour. Therefore, the assessment of one's behaviour through a KAP2 survey among targeted groups is significant.

In several research ventures, the past decade saw the rapid growth of the KAP2 study. Most of the KAP2 studies in Malaysia have been performed on food handlers, while limited studies of KAP2 have been conducted among consumers (Lim et al., 2015; Ruby et al., 2019a), especially during dining out. It is also essential to determine the understanding of the prevention of food poisoning, as it can influence the willingness of consumers to adapt and adopt the recommended healthy practices (Hosseintalaei et al., 2017). Consumers are the last in the food supply chain interaction, so food safety knowledge and practice play an essential role in outbreaks of foodborne diseases (Odeyemi et al., 2018). Dining out is the major contributor to the rise in Malaysian cases of food poisoning among consumers (Mahmood et al., 2018). To mitigate cases of food poisoning, awareness, attitude, practice, and understanding (KAP2) of food poisoning and its prevention during consumer dining out must be understood.

A KAP2 questionnaire on food poisoning and prevention is vital to be established during dining out among consumers. The most popular KAP2 studies on the prevention of food poisoning only involve the cooking ethics of food handlers and personal hygiene (Zulkifly et al., 2013; Ismail et al., 2016; Woh et al., 2016; Dora-Liyana et al., 2018), but not the attitude and preventive behaviour of consumers during dining out. Moreover, previous consumer-oriented research focused on food safety KAP2 food preparation analysis at home instead of food poisoning prevention during dining out (Mullan et al., 2015; Odeyemi et al., 2018; Ruby et al., 2019a; Ruby et al., 2019b; Ruby et al., 2019c; Mihalache et al., 2020). Furthermore, the previous studies did not include the cleanliness of food premises in their KAP2 questionnaire, which is essential, especially during dining out, to be included in a KAP2 questionnaire. Ungku Fatimah et al. (2011) supported the statement that, in addition to the hygiene of the food handler, the cleanliness of the food premise is one of the critical elements which affects consumers' preventive behaviour towards food poisoning while selecting a place to eat and while eating outside. Similarly, Mihalache et al. (2020) stated that the cleanliness and perception of food poisoning prevention environmental factors strongly influenced the preventative attitude. Hygiene of the food handlers and cleanliness of the food premises should therefore be included in the creation of the KAP2 questionnaire of food poisoning and its prevention during dining out.

To determine the prevention of food poisoning KAP2 during dining out, emphasis on the KAP2 research using a valid and reliable instrument is crucial. In comparison, most studies in different populations have demonstrated the use of inadequately designed and validated questionnaires. Some questionnaires were having insufficient information on validation procedures (Zainuddin et al., 2018). Besides, several previous studies do not use a validated questionnaire to test KAP2 (Khan et al., 2014). To identify the changes in knowledge and behaviour among respondents, it is crucial to use a valid and reliable questionnaire (Nik Rosmawati et al., 2015).

The validity and reliability review of the research methods used is vital to ensure the accuracy of the measuring instrument. Validity is the veracity of findings, and reliability is the stability of results (Mohajan, 2017). Cherry (2020) said it is crucial for the instrument to be valid for the correct interpretation and implementation of the findings. The tool is also correct if every prescribed variable is correctly controlled (Md Ghazali, 2016). Some forms of validity analyses can be performed, including face validity, content validity, construct validity, and the validity of criterion (Taherdoost, 2018). Reliability, on the other hand, is defined as the degree to which test scores are free of measurement errors (Md Ghazali, 2016). Reliability tests are essential since they relate to the coherence of a measuring device, and the alpha coefficient of the Cronbach is the most suitable reliability indicator when using a Likert scale (Taherdoost, 2018). Therefore, before the actual data collection, it is crucial to measure the validity and reliability of the KAP2 survey used in the present analysis.

To assess their knowledge, attitudes, practices and perception about food poisoning prevention while dining out, having a valid and reliable questionnaire is necessary before conducting any consumer education programme (Chen et al., 2013). To our best knowledge, no questionnaire on KAP2 on the food poisoning prevention during dining out has been published and developed with a validity and reliability review. The goal of the current study was, therefore, to establish a valid and reliable KAP2 survey on food poisoning and its prevention during dining out among the consumers. 


\section{Materials and methods}

\subsection{Study design and recruitment}

Terengganu has been chosen as a study location because the Malaysian Ministry of Health $(\mathrm{MOH})$ has reported that in 2019, the incident rate of food poisoning per 100000 population was the highest in Terengganu, with 68.9 in comparison with other states (MOH, 2019). Kuala Nerus was chosen in Terengganu because in this selected district, as announced by the Ministry of Domestic Trade and Consumer Affairs in 2018, there has been a rise in food poisoning cases (Has et al., 2018). Convenience sampling was used in the selection of consumers for this study.

The cross-sectional study is to validate the KAP2 questionnaire in the Gong Badak housing area, Kuala Nerus Terengganu, which took place from 28 October to 2 November 2019. Regarding the pilot study sample size, many pilot studies do not justify the acceptable pilot studies sample size (Henly, 2015). However, Whitehead et al. (2015) had mentioned that at least 30 respondents were sufficient for the pilot study. Besides, Julious (2005) carried out a sample size's thumb rule survey for a pilot project, which showed that 12 people were adequate to obtain a reliable mean and variance. Furthermore, previous pilot studies were performed with less than 30 respondents by DeMille et al. (2006), Neff and Germer (2013), and Singh et al. (2016). The current study recruits 30 consumers based on the requirements for inclusion and exclusion. The criteria for inclusion of participants were at least dining out once a week, 18 years and older, and can read and write in Malay. The questionnaire was submitted in Malay. In the meantime, those who answered the questionnaire halfway were disqualified and declined to participate.

To assess knowledge, attitude, practice and perception of food poisoning and its preventative effect among respondents, the self-administered questionnaire was completed. The Malay language was the common language used in Malaysia in the questionnaire (Awadh et al., 2014). Written informed consent was received from all respondents. Firstly, five minutes were taken to address the purpose of the analysis. The questionnaire took about 15 to $30 \mathrm{mins}$, including in the sociodemographic information areas. After the questionnaire was completed, a token of appreciation was given. Ethical approval for this study was gained from the human ethics committee of the Faculty of Medicine and Health Sciences, Universiti Putra Malaysia (UPM): JKEUPM-2019-302.

\subsection{Questionnaire development}

The questionnaire was prepared in a Malay as a local language used in Terengganu. The questionnaire was divided into five sections: the socio-demographic profile, knowledge, attitude, practice, and perception of food poisoning and its prevention. In improving the knowledge of food poisoning and its prevention, Zainuddin et al. (2018) had previously developed and validated a new leptospirosis questionnaire in Malaysia, reporting that the use of these six domains was essential to determine the level of knowledge about specific conditions. The six key domains were the aetiology of illness, high-risk foods, symptoms and signs, the complication, the diagnosis and prevention of food spoilage. Consequently, the knowledge of food poisoning prevention used in the current research was updated by improvements in previous studies by Low et al. (2016), Mahmood et al. (2018), and Ruby et al. (2019a) in these areas, and based on food poisoning. The knowledge on food poisoning prevention was assessed through closed-ended questions, which consist of 42 items and comprised of six main domains of disease aetiology (4 items), high-risk foods (10 items), food poisoning sign and symptoms (10 items), food poisoning complication (5 items), food spoilage detection (3 items), and food poisoning prevention (10 items). An example of a question used to assess food poisoning knowledge includes "the cause of food poisoning is bacteria: incorrect-correct-unsure". For evaluating the knowledge, the answers choices were "yes," "no," and "not sure". For every correct answer, a score of "1" will be given. Meanwhile, a score " 0 " will be given to every incorrect, unsure and unanswered question.

The construct attitude included one domain of behaviour-cognitive behaviour as the general attitude to avoid food poisoning during dining out, which Zainuddin et al. (2018) suggested. The attitude's item of Ismail et al. (2016) and Nik Rosmawati et al. (2016) changed in some way, as those studies had the general elements of food poisoning prevention. In the current study, attitude questions have been altered by taking into account food poisoning prevention as the principal elements in designing the KAP2 questionnaire, by tracking the cleanliness of food premises and food handlers' hygiene. The problem of spitting around food premises was also included in the food poisoning prevention construct. Spitting is known to contribute to the spread of infectious diseases in food environments (Serena, 2020). Therefore, the issue of spitting around food premises needs to be included in the KAP2 food poisoning prevention questionnaire during dining out. Thus, the attitude towards food poisoning prevention contained one domain with 10 items of general attitude towards food poisoning prevention of behavioural cognitive. An example of items used includes, "I will make sure to 
always wash my hands with soap before eating". The participants were requested to rate their agreement or disagreement by using the 5-Likert scale of " 1 = strongly disagree", "2 = disagree", "3 = neither agree nor disagree", " $4=$ agree", and " $5=$ strongly agree". The developed questions included negative statements alongside positive statements to avoid bias in answering the questions (Dora-Liyana et al., 2018). All points were summed up, and negative items were reversed scored.

The construct of the practice of food poisoning prevention during dining out consists of one main domain of preventive and risk-reduction infection practices, as suggested by Odeyemi et al. (2019) and Zainuddin et al. (2018). Thus, the questions on selfreported food poisoning prevention practices (13 items) were adapted with modifications from previous studies by Odeyemi et al. (2019), since the practice questions used in this previous study consist of food poisoning prevention practices. The food poisoning prevention practice was assessed through closed-ended questions. Similar to the construct attitude, the questions on the practice of food poisoning prevention during dining out were modified by including both food poisoning prevention by observing the cleanliness of food premises and food handler's hygiene. The developed questions included negative statements alongside positive statements to avoid bias in answering the questions (Dora-Liyana et al., 2018). The scoring of the 4-Likert scale used from "1 = never", "2 = seldom", "3 = sometime", to " $4=$ always". All points were summed up, and negative items were reversed scored.

The perception section used elements from the Health Belief Model (HBM): perceived barrier, perceived susceptibility, perceived severity, and perceived benefit (Hanson et al., 2015; Hosseintalaei et al., 2017). Previous research by Ab Rahman et al. (2018) supported the argument, which reported that KAP was affected by the way people viewed the sensitivity of diseases, the impediments to preventive practice and the advantages of preventive actions. Besides, HBM is a theoretical method used widely to analyse actions related to food safety (Hanson et al., 2015). Therefore, in the current study, the questions on perception towards food poisoning prevention were adapted with modification from previous studies by Gupta et al. (2018), Haapala et al. (2004), Hanson et al. (2015) and $\mathrm{Ng}$ et al. (2009), as consists of these HBM's constructs towards food poisoning and its prevention. The construct of risk perception consisted of 15 items and was divided into four main domains of perceived barrier (4 items), perceived susceptibility ( 5 items), perceived severity (2 items), and perceived benefit (4 items). The risk perception of food poisoning prevention was assessed through closed-ended questions. The 5-Likert scale was used from "1 = strongly disagree", "2 = disagree", "3 = neither agree nor disagree", " $4=$ agree", to " $5=$ strongly agree". All points were summed up, and negative items were reversed scored.

\subsection{Validity and reliability analysis}

A validity test to the questionnaires was done for the relevancy, content, language clarity, time needed to answer, and ease of understanding (Awad et al., 2017). The difficulty and discriminant index were analysed to determine the constructed knowledge (Nik Rosmawati et al., 2015). The total scores were ranked from the highest to the lowest (Mahjabeen et al., 2017). The difficulty index was calculated using the following formula: difficulty index $=$ (the number of correct answers to the knowledge items) / (the total number of answers consist of both correct and incorrect answers (Koo et al., 2016). A question was considered easy when the difficulty index was more than 0.7 , the value between $0.3-0.7$ was acceptable, and difficult when less than 0.3 (Karelia et al., 2013; Rao et al., 2016). The highest difficulty index's value, the easier the questions (Ahmad Fuad, 2010).

The discrimination index ranges between -1.00 and +1.00 (Hingorjo and Jaleel, 2012). The discrimination index below 0.20 considered as low, between 0.20-0.24 were accepted, 0.25-0.35 were considered as good, indices more than 0.35 were indicated as excellent (Karelia et al., 2013), and negative value up to 0.19 need to revise the question which considered as low (Ahmad Fuad, 2010). A highly discriminating item suggests that the item was correctly answered for students who had high scores, while students who had low test scores got the item wrong (Boopathiraj and Chellamani, 2013). The following formula was used to calculate the discrimination index: [(the number of respondents answering correctly in the upper group 27\%) - (the number of respondents answering correctly in the lower group 27\%)] / (the number of respondents in the upper or lower groups) (Ahmad Fuad, 2010; Fourie et al., 2010; Rosmawati et al., 2015; Koo et al., 2016; Mahjabeen et al., 2017). The top $27 \%$ were considered the upper group with high marks, and the bottom $27 \%$ were considered the lower group with lower marks. (Nik Rosmawati et al., 2015). In item analysis based on Kelly's (1939) derivation, the upper and lower $27 \%$ rule is widely used. As a percentage of the upper $27 \%$ and lower $27 \%$ of the total category, the difference between the correct answers can be determined whether an item discriminated against high scorers and low scorers on the test. Moreover, most of the previous studies used $27 \%$ in their discrimination index's calculation as a perfect balance between two groups of upper and lower groups (Nik Rosmawati et al., 2015; Koo et al., 2016; Abdullah 
et al., 2019). Therefore, $27 \%$ of respondents in the upper and lower category who replied correctly were included for the calculation of the discriminant index in the current study.

The construct validity was used to construct attitude, practice, and perception. Albuquerque et al. (2014), Squires et al. (2011), and Tapsir et al. (2018) had stated four critical metrics used to validate the construct: Cronbach's alpha, inter-item correlation $(>0.30)$, itemtotal correlation ( $>0.30$ ), and Cronbach's alpha if item deleted. The measurements used can help the researcher delete or retain each construct's questionnaire (Hajjar, 2018). After conducting the validity test, the reliability analysis was done for each of the constructs' remaining items. Montshiwa et al. (2014) and Ursachi et al. (2015) had reported the following rules of thumb to describe Cronbach's alpha: less than 0.5 indicates unacceptable, 0.6-0.7 indicates an acceptable level, and 0.8 or greater stated an excellent level of reliability.

\subsection{Statistical analysis}

The data analysis, validation, and reliability of the questionnaire were conducted using SPSS 22. The data were analysed using descriptive statistics and presented as frequency and percentage for categorical data.

\section{Results}

\subsection{Demographic result}

Table 1 presents the frequency distribution of sociodemographic characteristics among 30 respondents used in the pilot study. Majority of the respondents were female, with $90.0 \%$, and the age group of 20-29 years old with $66.7 \%$. All of the respondents were Malay. More than half the respondents were single $(66.7 \%)$ and had tertiary academic qualification $(60.0 \%)$. About $66.7 \%$ of the respondents were unemployed. Majority of the respondents had an income level of less than RM499, with $73.3 \%$ due to the unemployed.

\subsection{Knowledge of food poisoning and its prevention}

The difficulty index and discrimination index for each item in construct knowledge of food poisoning are presented in Table 2 . The difficulty index showed that out of 42 items, 28 items were too easy, three items were difficult, and the remaining 11 items were within an acceptable range. The discrimination index for 42 items showed 28 items with low discrimination power, three items showed good discrimination, and 11 items exhibited excellent discrimination. Hence, the final items for construct knowledge were 42 items with disease aetiology (4 items), high-risk foods (10 items), food poisoning sign and symptoms (10 items), food poisoning complication (5 items), food spoilage detection (3 items), and food poisoning prevention (10 items).

\subsection{Attitude towards food poisoning prevention}

Table 1. Frequency distribution of sociodemographic characteristics $(n=30)$

\begin{tabular}{lc}
\hline \multicolumn{1}{c}{ Characteristics } & $\mathrm{n}(\%)$ \\
\hline Gender & $3(10.0)$ \\
\hline Female & $27(90.0)$ \\
Male & $1(3.3)$ \\
\hline Age & $20(66.7)$ \\
\hline$\leq 19$ years & $1(3.3)$ \\
$20-29$ years & $3(10.0)$ \\
$30-39$ years & $5(16.7)$ \\
$40-49$ years & \\
$\geq 50$ years & $30(100.0)$ \\
\hline Ethnic & $20(66.7)$ \\
\hline Malay & $10(33.3)$ \\
\hline Marital Status & \\
\hline Single & $11(36.7)$ \\
Married & $1(3.3)$ \\
\hline Academic Qualification & $18(60.0)$ \\
\hline Secondary school and lower & \\
STPM/A-level/ GCE/Diploma & $1(3.3)$ \\
Tertiary (degree/master/Phd) & $7(23.3)$ \\
\hline Job Sector & $2(6.7)$ \\
\hline Self-employed & $20(66.7)$ \\
Government sector & $22(73.3)$ \\
Private sector & $4(13.3)$ \\
Unemployed & $4(13.3)$ \\
\hline Monthly Income & \\
\hline$\leq$ RM 499 & \\
RM 500 - RM 999 & RM 1000 \\
\hline & \\
\hline
\end{tabular}

Table 3 displays the item-total statistics table, which includes the corrected item-total correlation and value of Cronbach's alpha if the item were deleted. The results showed that the corrected item-total correlation value for item 1 , item 4 , item 6 , item 7 , and item 12 was $<0.30$, which indicates these items should be deleted. By deleting these items, the Cronbach's alpha, if the item was deleted, increased from 0.729 to $0.741,0.722,0.736$, and 0.758. Even if Cronbach's alpha was still in the appropriate range by removing these objects, the items must be removed because the low inter-item and itemtotal correlation suggest that the items in the same build were not very well correlated. Therefore, the remaining items for construct attitude were ten. After removing five attitude items, the overall Cronbach's alpha value was 0.848 indicates an excellent level of reliability.

\subsection{Practice towards food poisoning prevention}

Table 4 provides the result of construct validity on the construct of practice towards food poisoning 
Table 2. Food poisoning knowledge item analysis $(\mathrm{n}=30)$

Questions no.

Knowledge of disease aetiology

K1a - The cause of food poisoning is bacteria

$\mathrm{K} 1 \mathrm{~b}$ - The cause of food poisoning is a virus

$\mathrm{K} 1 \mathrm{c}$ - The cause of food poisoning is a parasite

$\mathrm{K} 1 \mathrm{~d}$ - The cause of food poisoning is pesticide residue

Knowledge of high-risk foods

K2a - High-risk food is poultry

$\mathrm{K} 2 \mathrm{~b}$ - High-risk food is meat

$\mathrm{K} 2 \mathrm{c}$ - High-risk food is bread

$\mathrm{K} 2 \mathrm{~d}$ - High-risk food is dried foods

$\mathrm{K} 2 \mathrm{e}$ - High-risk food is dairy products

$\mathrm{K} 2 \mathrm{f}$ - High-risk food is seafood

$\mathrm{K} 2 \mathrm{~g}$ - High-risk food is rice

$\mathrm{K} 2 \mathrm{~h}$ - High-risk food is canned foods while unopened/indented

Difficulty Discrimination index index

0.90

0.53

0.43

0.70

0.40

0.50

0.50

0.62

Action

$\mathrm{K} 2 \mathrm{i}$ - High-risk food is vegetables

$\mathrm{K} 2 \mathrm{j}$ - High-risk food is fruits

0.93

0.00

0.00

0.96

0.87

0.40

$-0.25$

0.90

0.25

0.83

0.00

0.76

0.75

0.53

$-0.37$

0.86

$-0.37$

0.50

0.50

0.36

0.37

Food poisoning signs and symptoms

$\mathrm{K} 3 \mathrm{a}$ - A symptom of food poisoning is diarrhoea

$\mathrm{K} 3 \mathrm{~b}$ - A symptom of food poisoning is vomiting

1.00

1.00

0.00

1.00

0.00

0.30

0.00

$\mathrm{K} 3 \mathrm{~d}$ - A symptom of food poisoning is dryness of lips

0.90

0.25

$\mathrm{K} 3 \mathrm{e}$ - A symptom of food poisoning is lethargy

1.00

0.12

$\mathrm{K} 3 \mathrm{f}$ - A symptom of food poisoning is yellow eyes (jaundice)

$\mathrm{K} 3 \mathrm{~g}$ - A symptom of food poisoning is fever

0.60

0.00

0.40

$-0.12$

$\mathrm{K} 3 \mathrm{~h}$ - A symptom of food poisoning is bloody stool

$\mathrm{K} 3 \mathrm{i}$ - A symptom of food poisoning is muscle pain

0.16

0.65

$\mathrm{K} 2 \mathrm{j}$ - A symptom of food poisoning is gum bleeding

1.00

0.50

0.00

\begin{tabular}{lll}
0.80 & 0.50 & Included \\
0.06 & 0.25 & Included \\
0.10 & 0.12 & Included \\
0.93 & 0.00 & Included \\
0.70 & 0.12 & Included \\
\hline
\end{tabular}

Food poisoning complication

$\mathrm{K} 4 \mathrm{a}$ - A food poisoning complication is a death

$\mathrm{K} 4 \mathrm{~b}$ - A food poisoning complication is kidney failure

$\mathrm{K} 4 \mathrm{c}$ - A food poisoning complication is liver failure

$\mathrm{K} 4 \mathrm{~d}$ - A food poisoning complication is a dehydration

0.70

0.12

Included

\section{Spoil food detection}

K5a - Physical change of food

$\mathrm{K} 5 \mathrm{~b}$ - Food smells foul

0.93

0.12

0.00

0.96

0.00

K5c - Change of the food taste

1.00

Food poisoning prevention

K6a - Ensure the food is thoroughly cooked

K6b - Using the same cloth to wipe countertop and plates

0.96

0.12

0.93

0.00

0.90

0.12

K6d - Washing eggs before cooking

0.96

0.12

K6e - Washing hands using soaps each time after using the toilet

0.96

0.12

K6f - Washing hand using liquid soap

0.96

0.12

$\mathrm{K} 6 \mathrm{~g}$ - Eating cooked food that is kept at room temperature for 12-24 hours

0.96

0.12

1.00

0.00

K6h - Raw food should be kept separate from cooked food

1.00

0.00

K6j - Practice good personal hygiene

1.00

0.00

Included

Included Included

$\mathrm{K}=$ Knowledge's items (42 items)

prevention. Table 4 shows that the corrected item-total correlation value for item 4 , item 6 , and item 9 were $<0.30$. By deleting these items, the Cronbach's alpha increased from 0.757 to $0.762,0.763$ and 0.764 .

Therefore, item 4, item 6 , and item 9 were removed, making the finalized questions in construct practice ten. The overall Cronbach's alpha value after removing items, three practice items was 0.780 indicates an acceptable 
Table 3. Item-total-statistic of attitude towards food poisoning prevention $(\mathrm{n}=30)$

\begin{tabular}{|c|c|c|c|c|}
\hline Question no. & $\begin{array}{l}\text { Range inter- } \\
\text { item correlation } \\
\text { value }\end{array}$ & $\begin{array}{l}\text { Corrected item- } \\
\text { total correlation }\end{array}$ & $\begin{array}{l}\text { Cronbach's } \\
\text { alpha if item } \\
\text { deleted }\end{array}$ & Action \\
\hline \multicolumn{5}{|l|}{ Behaviour-cognitive } \\
\hline $\begin{array}{l}\text { A1 - I do not worry if there are pests (such as rodents, } \\
\text { cockroaches, and flies) in the food premises that I visit. }\end{array}$ & $0.079-0.253$ & 0.05 & 0.741 & Deleted \\
\hline $\begin{array}{l}\text { A2 - I do care if I see food handlers smoking while preparing or } \\
\text { handling food. }\end{array}$ & $0.483-0.524$ & 0.404 & 0.709 & Remained \\
\hline $\begin{array}{l}\text { A3 - I will choose the food premise of the food handlers that wear } \\
\text { a glove while handling food. }\end{array}$ & $0.308-0.640$ & 0.425 & 0.707 & Remained \\
\hline $\begin{array}{l}\text { A5 - I will not choose the food premise of which the food } \\
\text { handlers' nails are not trimmed. }\end{array}$ & $0.308-0.529$ & 0.415 & 0.705 & Remained \\
\hline $\begin{array}{l}\text { A6 - I do not care if the food handlers do not wear an apron while } \\
\text { handling food. }\end{array}$ & $0.034-0.266$ & 0.124 & 0.736 & Deleted \\
\hline $\begin{array}{l}\text { A7 - I will not choose the food premise of which the food handlers } \\
\text { do not wear a headcover. }\end{array}$ & $0.105-0.174$ & -0.337 & 0.787 & Deleted \\
\hline $\begin{array}{l}\text { A } 8 \text { - I will ensure the premise hygiene grade while deciding on } \\
\text { choosing a food premise. }\end{array}$ & $0.318-0.642$ & 0.785 & 0.668 & Remained \\
\hline $\begin{array}{l}\text { A9 - I will not purchase cooked food that is left at room } \\
\text { temperature for an extended period. }\end{array}$ & $0.306-0.483$ & 0.376 & 0.71 & Remained \\
\hline A10 - I will ensure the food premise that I visited is clean. & $0.389-0.798$ & 0.753 & 0.682 & Remained \\
\hline $\begin{array}{l}\text { A11 - I will always ensure to wash my hands with soap before } \\
\text { eating. }\end{array}$ & $0.314-0.701$ & 0.691 & 0.683 & Remained \\
\hline A12 - I do not worry if I exhibit symptoms of food poisoning. & $0.014-0.253$ & -0.171 & 0.758 & Deleted \\
\hline $\begin{array}{l}\text { A13 - I will lodge a report to relevant authorities (e.g., local } \\
\text { authority) if I witness unhygienic food handling activities and } \\
\text { preparation in the food premise. }\end{array}$ & $0.427-0.620$ & 0.531 & 0.696 & Remained \\
\hline $\begin{array}{l}\text { A14 - I will inform the relevant authorities (e.g., health authorities } \\
\text { or local authorities) if I contracted food poisoning. }\end{array}$ & $0.306-0.674$ & 0.487 & 0.698 & Remained \\
\hline A15 - I need to see a doctor if I exhibit food poisoning symptoms. & $0.306-0.712$ & 0.758 & 0.684 & Remained \\
\hline
\end{tabular}

A = Attitude's items (15 items)

Table 4. Item-total-statistic of practice towards food poisoning prevention $(n=30)$

\begin{tabular}{|c|c|c|c|c|}
\hline Question no. & $\begin{array}{c}\text { Range inter- } \\
\text { item correlation } \\
\text { value }\end{array}$ & $\begin{array}{l}\text { Corrected item- } \\
\text { total correlation }\end{array}$ & $\begin{array}{c}\text { Cronbach's } \\
\text { alpha if item } \\
\text { deleted }\end{array}$ & Action \\
\hline \multicolumn{5}{|l|}{ Preventive and risk-reduction infection practices } \\
\hline P1 - I wash my hand clean before eating & $0.300-0.647$ & 0.508 & 0.743 & Remained \\
\hline P2 - I will use liquid soap over the bar when washing my hands. & $0.333-0.399$ & 0.392 & 0.741 & Remained \\
\hline P3 - I do not spit around the food premise. & $0.303-0.372$ & 0.440 & 0.759 & Remained \\
\hline $\begin{array}{l}\text { P4 - I reject food premises that harbour pests (rodents, } \\
\text { cockroaches, and flies). }\end{array}$ & $0.015-0.201$ & 0.037 & 0.762 & Deleted \\
\hline $\begin{array}{l}\text { P5 - I reject food premises of which the food handlers are smoking } \\
\text { during food handling. }\end{array}$ & $0.335-0.553$ & 0.424 & 0.739 & Remained \\
\hline P6 - I choose clean food premises & $0.014-0.074$ & 0.026 & 0.763 & Deleted \\
\hline $\begin{array}{l}\text { P7 - I look for the cleanliness grade before entering the food } \\
\text { premises }\end{array}$ & $0.321-0.489$ & 0.301 & 0.749 & Remained \\
\hline P8 - I will see the doctor if I exhibit food poisoning symptoms & $0.411-0.647$ & 0.490 & 0.732 & Remained \\
\hline $\begin{array}{l}\text { P9 - I do not choose food premises where the cooked food is left } \\
\text { at room temperature for an extended period. }\end{array}$ & $0.008-0.248$ & 0.102 & 0.764 & Deleted \\
\hline $\begin{array}{l}\text { P10 - I reject the food premises of which the food handlers do not } \\
\text { wear an apron while handling food. }\end{array}$ & $0.301-0.630$ & 0.716 & 0.695 & Remained \\
\hline $\begin{array}{l}\text { P11 - I will not choose the food premises where the food handlers } \\
\text { do not wear a glove while handling food. }\end{array}$ & $0.303-0.776$ & 0.677 & 0.705 & Remained \\
\hline $\begin{array}{l}\text { P12 - I reject food premises of which the food handlers do not } \\
\text { wear headcovers. }\end{array}$ & $0.300-0.776$ & 0.521 & 0.725 & Remained \\
\hline P13 - I will smell the food to ensure the food is not spoilt. & $0.301-0.333$ & 0.335 & 0.748 & Remained \\
\hline
\end{tabular}

$\mathrm{P}=$ Practice's items (13 items) 
value of reliability.

\subsection{Perception of food poisoning prevention}

Table 5 presents the corrected item-total correlation value for construct practice and showed item 3 , item 5 , item 8 , item 9 , item 10 , item 11 , item 12 , item 13 , item 14 , and item 15 were $<0.30$. If these items were deleted, the Cronbach's alpha value increased from 0.582 to 0.611 as a new Cronbach's alpha for whole construct perception. Therefore item 3 , item 5 , item 8 , item 9 , item 10 , item 11, item 12, item 13, item 14, and item 15 were removed from the construct of perception. The total question remaining for construct perception was five, and the overall Cronbach's alpha after removing these five perception items was 0.611 , which indicates an acceptable value of reliability.

\section{Discussion}

The present study aimed to establish and assess the validity and the reliability of the KAP2 survey on food poisoning and its prevention among consumers. Many KAP2 studies on food safety and hygiene have been performed. Nevertheless, there have been limited consumer studies, particularly on the prevention of food poisoning while dining out. Also, consumers' knowledge

of food poisoning when eating outside should be measured to have a direct effect on the preventive behaviour of consumers (Hosseintalaei et al., 2017). Similarly, an earlier study by Ab Rahman et al. (2018) was backed by the assertion, which stated that consumer perceptions of diseases widely influence KAP.

The knowledge items were assessed using difficulties and discriminating indexes in the present study. It is necessary to calculate these indexes to validate the knowledge construct. Similarly, the previous study by Quaigrain and Arhin (2017) had supported this argument in which the difficulty and discrimination indices are the tools that be used to check whether the construct is well constructed or not. These analyses can help the researchers determine the items that are considered acceptable and those that need to be deleted, improved or remained. The item difficulty was used to differentiate challenging items from the simple ones (Koo et al., 2016). The discrimination index relates to how well an instrument distinguishes between the respondents who get high and low scores (Hotiu, 2006) and distinguishes between the respondents who are knowledgeable or not (Fourie et al., 2010).

The difficulty and discrimination indices are often Table 5. Item-total-statistic of perception towards food poisoning prevention $(n=30)$

\begin{tabular}{|c|c|c|c|c|}
\hline Question no. & $\begin{array}{l}\text { Range inter-item } \\
\text { correlation value }\end{array}$ & $\begin{array}{l}\text { Corrected item- } \\
\text { total correlation }\end{array}$ & $\begin{array}{l}\text { Cronbach's alpha } \\
\text { if item deleted }\end{array}$ & Action \\
\hline \multicolumn{5}{|l|}{ Perceived barrier } \\
\hline $\begin{array}{l}\text { PR1 - I think that it is time-consuming to choose clean food } \\
\text { premises }\end{array}$ & $0.338-0.446$ & 0.315 & 0.545 & Remained \\
\hline $\begin{array}{l}\text { PR2 - I feel that getting treatment in a hospital or clinic due to } \\
\text { food poisoning is inconvenient }\end{array}$ & $0.292-0.583$ & 0.305 & 0.548 & Remained \\
\hline PR3 - I believe that to get safe food requires high costs. & $0.021-0.101$ & 0.185 & 0.586 & Deleted \\
\hline PR4 - I believe that to ensure the cleanliness of food premises & $0.292-0.557$ & 0.36 & 0.532 & Remained \\
\hline \multicolumn{5}{|l|}{ Perceived susceptibility } \\
\hline PR5 - I feel that the risk of me getting food poisoning in & $0.044-0.211$ & 0.036 & 0.603 & Deleted \\
\hline PR6 - I think foods that I take daily are safe to be consumed & $0.345-0.814$ & 0.596 & 0.513 & Remained \\
\hline $\begin{array}{l}\text { PR7 - I think the drinks that I take daily are safe to be } \\
\text { consumed. }\end{array}$ & $0.366-0.814$ & 0.555 & 0.501 & Remained \\
\hline $\begin{array}{l}\text { PR8 - I feel that my odds of developing food poisoning are very } \\
\text { low. }\end{array}$ & $0.176-0.464$ & 0.05 & 0.595 & Remained \\
\hline $\begin{array}{l}\text { PR9 - I feel that my risk of getting food poisoning is small due } \\
\text { to the food prepared by food handlers who practice good } \\
\text { personal hygiene. }\end{array}$ & $0.044-0.107$ & 0.194 & 0.57 & Deleted \\
\hline \multicolumn{5}{|l|}{ Perceived severity } \\
\hline PR10 - Food poisoning can be life-threatening. & $0.013-0.192$ & 0.067 & 0.586 & Deleted \\
\hline PR11 - I think unsafe food can make people sick. & $0.173-0.248$ & 0.206 & 0.571 & Deleted \\
\hline \multicolumn{5}{|l|}{ Perceived benefit } \\
\hline PR12 - I believe proper food safety practices reduce the risk of & $0.040-0.193$ & 0.123 & 0.579 & Deleted \\
\hline $\begin{array}{l}\text { PR13 - I believe that clean food premises can attract more } \\
\text { consumers. }\end{array}$ & $0.075-0.181$ & 0.188 & 0.574 & Deleted \\
\hline $\begin{array}{l}\text { PR14 - I think that hygiene and safe-to-consume food are } \\
\text { usually sold at a reasonable price. }\end{array}$ & $0.366-0.664$ & 0.212 & 0.567 & Deleted \\
\hline PR15 - I believe that safe and clean foods are easy to access. & $0.305-0.644$ & 0.083 & 0.586 & Deleted \\
\hline
\end{tabular}

$\mathrm{PR}=$ Perception's items (15 items) 
commonly related (Hingorjo and Jaleel, 2012). Gajjar et al. (2014) had reported that too difficult (wrongly answered by everyone) and too easy question (correctly answered by everyone) will have a low discrimination index, as difficult to distinguish the knowledgeable respondents. Similarly, the items of knowledge in the present study showed high difficulty indices (easy questions) with a low discrimination index. The present study showed that 25 knowledge items had a poor discrimination index $(<0.20)$ with a high value of difficulty index indicating that the questions were easy but unable to correctly answered by respondents. Meanwhile, any discrimination index of 0.2 or higher is acceptable and the test item would be able to differentiate between the weak and good students (Karelia et al., 2013). With a negative value of the discriminatory index in this analysis, three questions of "K2d High-risk foods are dried foods", "K2h High-risk foods in canned when unopened or indented", and "K3g A symptom of food poisoning is fever" should be deleted in the present study. Koo et al. (2016) stated that the discrimination index below 0.2 should be eliminated. Besides, Gajjar et al. (2014) had reported that several studies have shown a negative discrimination index. The low and negative discrimination index commonly caused by the wrong key, ambiguous framing of question or generalized poor preparation of respondents prior to answering the questions (Gajjar et al., 2014). These three questions were included in the current study due to the high difficulty indices (easy questions) and provided the relationships and the relevance to the current analysis, as indicated by Ahmad Fuad (2010) and Chen et al. (2013). It is therefore essential to classify the appropriate items for the study and interpret the findings with caution to prevent the deletion of critical items.

The construct's validity was carried out in the field of attitude, practice and perception. The validity of the construct is used to determine whether all measuring variables exist or are omitted for all other parts of the system (Hajjar, 2018). Inter-item correlation is generally used in the same construct to calculate well-correlated objects. In addition, to determine the homogeneity of the items, item-total and inter-item correlations were used (Moser et al., 2009). In the current analysis, items with inter-item and item-total correlation value $<0.3$ were discarded as the items did not reflect the same build material, while items with inter-item and item-total correlation value $>0.3$ remained. Likewise, previous studies by Heo et al. (2015) and Moser et al. (2009) recorded the value of inter-item correlation and itemtotal correlation $>0.3$ indicating an adequate contribution and correlation of all items to the measure and should be remained. Hajjar (2018) also had reported that the corrected overall correlation of over 0.3 suggests that the scores of each item are positive and positively correlated to the other two's combined score. Therefore, according to the present study findings, certain artefacts in design, practice and interpretation have been deleted as these items are not very well associated based on the importance of the overall correlation and the importance of Cronbach alpha has been increased if the items are deleted. In the current analysis, five items of construct attitude, three items for practise, and ten items for construct perception were deleted. The current study showed that the value of Cronbach's alpha increased to suggest these items could be deleted. It has the same agreement with Hajjar (2018) which noted that if it has a very low inter-item and item-total correlation, the items should be deleted, even when deleting the items, the alpha value of the Cronbach increases a little bit and is still in the range of appropriate value.

The remaining elements in each attitude, practice and perception construct were evaluated for reliability analysis. It is said to have high reliability of internal consistency if the scale elements measure the same construct (Taherdoost, 2018). The reliability test needs to be carried out by referring to Cronbach's alpha values for internal consistency after the validity test is performed. Internal consistency involves the degree to which the same thing is measured by objects on the test or instrument (Bolarinwa, 2015). The most widely used Cronbach's alpha coefficient is for evaluating internal consistency (Taherdoost, 2018). It is, therefore, the present study used Cronbach's alpha coefficient for the reliability analysis. The present study showed that reliability is appropriate and suggested that the KAP2 questionnaire used is accurate in the assessment of food poisoning and food avoidance, attitude, practice and perception among consumers.

It is the first questionnaire developed to evaluate the level of KAP2 towards food poisoning and its prevention during dining out among consumers, to the best of our knowledge. It is crucial to take into account the potential bias in these responses. As Kocdar et al. (2016) stated, the results may be partial because respondents can guess the answer, even if they do not know the answers. The present research was also restricted to the consumer's dining activity in Terengganu. It is therefore proposed that a replication study can be carried out in other states to assess the validity and reliability of this questionnaire in future. Therefore, future research on the current subject is recommended.

\section{Conclusion}

The current pilot study showed that the KAP2 questionnaire developed is a valid and reliable tool to 
measure consumer knowledge, attitude, practice and perception of food poisoning and its prevention during dining out. This questionnaire covered the critical elements to avoid food poisoning when dining out. The validated questionnaire will indirectly improve consumers' knowledge, attitude, practice and realistic perception of preventing poisoning while eating out in future intervention research.

\section{Conflict of interest}

The authors declare no competing interests.

\section{Acknowledgements}

This study was funded under the Malaysia Research University Network (MRUN) UPM grant: UPM/8004/11/MRUN/2018/5539240.

\section{References}

Abdullah, M., Maulahela, H., Utari, A.P., Kusumo, P.D., Soebandrio, A., Achmad, I. and Makmun, D. (2019). Validity and Reliability of the Patient Assessment of Constipation: Symptoms (PAC-SYM (C) in the Indonesian Language. IOP Conference Series: Earth and Environmental Science, 248(1), 012060. https:// doi.org/10.1088/1755-1315/248/1/012060

Ahmad Fuad, A.R. (2010). What Those Numbers Mean: A guide to item analysis. Malaysia: KKMED Publications Medical Education Department School of Medical Sciences, Universiti Sains Malaysia Health Campus.

Albuquerque, C., Franco, V., Castro, F. and Oliveira, C. (2014). Cross-cultural adaptation and validation of the Portuguese version of the "European Health and Behaviour Survey-section B." Atencion Primaria, 46 (S5), 112-117. https://doi.org/10.1016/S0212-6567 (14)70076-9

Ali, A.N., Jie, J.S., Prajapati, S.K., Ahmed, N.Z., Iqbal, M.Z. and Alshammari, T.M. (2018). A KAP study on food safety and hygiene among private university students in Kedah state, Malaysia. Journal of Natural Remedies, 18(3), 113-121. https:// doi.org/10.18311/jnr/2018/22289

Awad, A., El-Shafei, D.A., Abdelsalam, A.E. and Sheta, S.S. (2017). Knowledge, Attitude and Practice of Female Teachers regarding Safe Food Handling; Is It Sufficient? An Intervention Study, Zagazig, Egypt. Egyptian Journal of Occupational Medicine, 41(2), 271-287.

Awadh, A.I., Hassali, M.A., Al-Lela, O.Q., Bux, S.H., Elkalmi, R.M. and Hadi, H. (2014). Immunization knowledge and practice among Malaysian parents: A questionnaire development and pilot-testing. $B M C$ Public Health, 14(1), 1-7. https:// doi.org/10.1186/1471-2458-14-1107

Bolarinwa O.A. (2015). Review Article: Principles and Methods of Validity and Reliability Testing of Questionnaires Used in Social and Health Science Research. Nigerian Postgraduate Medical Journal, 22(4), 195-201. https://doi.org/10.4103/11171936.173959

Boopathiraj, C. and Chellamani, K. (2013). Analysis of Test Items on Difficulty Level and Discrimination Index in the Test for Research in Education. International Journal of Social Science and Interdisciplinary Research, 2(2), 189-193.

Chen, S.T., Soo, K.L., Ab Rahman, A., Van Rostenberghe, H. and Harith, S. (2013). Development and pilot testing of nutrition knowledge, attitude and practice questionnaire in persons with disabilities (KAP-nOKU) among trainers in rehabilitation centres, Malaysia. Pakistan Journal of Nutrition, 12(8), 708-714. https:// doi.org/10.3923/pjn.2013.708.714

Cherry, K. (2020). Why Validity Is Important to Psychological Tests. Retrieved October 15, 2020, from Very Well Mind website: https:// www.verywellmind.com/what-is-validity-2795788

De Pretto, L., Acreman, S., Ashfold, M.J., Mohankumar, S.K. and Campos-Arceiz, A. (2015). The Link between Knowledge, Attitudes and Practices in Relation to Atmospheric Haze Pollution in Peninsular Malaysia. PLoS ONE, 10(12), e0143655. https://doi.org/10.1371/journal.pone.0143655

DeMille, D., Deming, P., Lupinacci, P. and Jacobs, L.A. (2006). The effect of the neutropenic diet in the outpatient setting: A pilot study. Oncology Nursing Forum, 33(2), 337-343. https://doi.org/10.1188/ ONF.06.337-343

Dora-Liyana, A.L., Mahyudin, N.A., Ismail-Fitry, M.R., Ahmad-Zaki, A. and Rasiyuddin, H. (2018). Food Safety and Hygiene Knowledge, Attitude and Practices among Food Handlers at Boarding Schools in the Northern Region of Malaysia. International Journal of Academic Research in Business and Social Sciences, 8(17), 238-266. https:// doi.org/10.6007/IJARBSS/v8-i17/5228

Fourie, S., Summers, B. and Zweygarth, M. (2010). Difficulty and discrimination indices as quality assurance tools for assessments in a South African problem-based pharmacy programme. Pharmacy Education, 10(2), 119-128

Gajjar, S., Sharma, R., Kumar, P. and Rana, M. (2014). Item and test analysis to identify quality multiple choice questions (MCQS) from an assessment of 
medical students of Ahmedabad, Gujarat. Indian Journal of Community Medicine, 39(1), 17-20. https://doi.org/10.4103/0970-0218.126347

Gupta, V., Khanna, K. and Gupta, R. K. (2018). A study on the street food dimensions and its effects on consumer attitude and behavioural intentions. Tourism Review, 73(3), 374-388. https:// doi.org/10.1108/TR-03-2018-0033

Haapala, I. and Probart, C. (2004). Food safety knowledge, perceptions, and behaviors among middle school students. Journal of Nutrition Education and Behavior, 36(2), 71-76. https:// doi.org/10.1016/S1499-4046(06)60136-X

Hajjar, S.T.EL. (2018). Statistical Analysis: InternalConsistency Reliability and Construct Validity. International Journal of Quantitative and Qualitative Research Methods, 6(1), 27-38.

Hanson, J.A., Hughes, S.M. and Liu, P. (2015). Use of health belief model variables to examine selfreported food handling behaviors in a sample of U.S. adults attending a tailgate event. Journal of Food Protection, 78(12), 2177-2183. https:// doi.org/10.4315/0362-028X.JFP-15-077

Has, S.M.C., Jaafar, S.N.A. and Chilek, T.Z.T. (2018). An assessment on pre-and post-food hygiene training on food safety's Kap level among food handlers in Kuala Terengganu and Kuala Nerus. Malaysian Applied Biology, 47(4), 61-69.

Henly, S.J. (2015). Routledge International Handbook of Advanced Quantitative Methods in Nursing Research. 1st ed. London: Routledge. https:// doi.org/10.4324/9781315882307

Heo, S., Moser, D.K., Pressler, S.J., Dunbar, S.B., Martin, G.M. and Lennie, T.A. (2015). The Psychometric Properties of the Symptom Status Questionnaire-Heart Failure. Journal of Cardiovascular Nursing, 30(2), 136-144. https:// doi.org/10.1097/JCN.0000000000000102

Hingorjo, M.R. and Jaleel, F. (2012). Analysis of onebest MCQs: The difficulty index, discrimination index and distractor efficiency. Journal of the Pakistan Medical Association, 62(2), 142-147.

Hosseintalaei, M., Shahnazi, H. and Mohammadi, M. (2017). The relationship of perceived susceptibility and self-efficacy with the decayed, missing, and filled teeth in pregnant women: a study based on the health belief model. Biomedical Research, 28(18), 8142-8148.

Hotiu, A. (2006). The Relationship Between Item Difficulty Indices in Multiple-Choice Tests in A Physical Science Course. Boca Raton, Florida, USA: Florida Atlantic University. MSc. Thesis
Ismail, F.H., Chik, C.T., Muhammad, R. and Yusoff, N.M. (2016). Food Safety Knowledge and Personal Hygiene Practices amongst Mobile Food Handlers in Shah Alam, Selangor. Procedia - Social and Behavioral Sciences, 222, 290-298. https:// doi.org/10.1016/j.sbspro.2016.05.162

Julious, S.A. (2005). Sample size of 12 per group rule of thumb for a pilot study. Pharmaceutical Statistics, 4 (4), 287-291. https://doi.org/10.1002/pst.185

Karelia, B.N., Pillai, A. and Vegada, B.N. (2013). The levels of difficulty and discrimination indices and relationship between them in four-response type multiple choice questions of pharmacology summative tests of Year II M.B.B.S students. IeJSME, 7(2), 41-46.

Kelly, T.L. (1939). Interpreting The Item Analysis Report. Journal of Educational Psychology, 30, 1724.

Khan, Y.H., Sarriff, A., Khan, A.H. and Mallhi, T.H. (2014). Knowledge, attitude and practice (KAP) survey of osteoporosis among students of a tertiary institution in Malaysia. Tropical Journal of Pharmaceutical Research, 13(1), 155-162. https:// doi.org/10.4314/tjpr.v13i1.22

Koo, H.C., Poh, B.K. and Ruzita, A.T. (2016). Development, validity and reliability of a questionnaire on knowledge, attitude and practice (KAP) towards whole grain among primary school children in Kuala Lumpur, Malaysia. International Food Research Journal, 23(2), 797-805.

Lim, T., Yee, F., Rosni, M. and Mohd, N. (2015). A Structural Modeling on Food Safety Knowledge, Attitude, and Behaviour Among Bum Bum Island community of Semporna, Sabah A structural modeling on food safety knowledge, attitude, and behaviour among Bum Bum Island community of Semporna, Sabah. Food Control, 60, 241-246. https://doi.org/10.1016/j.foodcont.2015.07.042

Low, W.Y., Jani, R., Halim, H.A., Alias, A.A. and Moy, F.M. (2016). Determinants of food hygiene knowledge among youths: A cross-sectional online study. Food Control, 59, 88-93. https:// doi.org/10.1016/j.foodcont.2015.04.032

Ministry of Health Malaysia. (2019). Health facts 2019. Malaysia: $\mathrm{MOH}$

Mahjabeen, W., Alam, S., Hassan, U., Zafar, T., Butt, R., Konanin, S. and Rizvi, M. (2017). Analysis of Multiple- Choice Questions: Item Difficulty, Discrimination Index and Distractor Efficiency. Annals of PIMS, 9, 310-315. https:// doi.org/10.5958/0974-9357.2017.00079.4

Mahmood, K., Khalid, J., Kamilah, H., Janee Ali, A., 
Muhammad, L. and Ariffin, F. (2018). An Empirical Study of Food Safety, Food Handling, and Food Poisoning Awareness Among Foreign Students in Penang, Malaysia. International Journal on Advanced Science Engineering Information Technology, 8(1), 150-156. https://doi.org/http:// dx.doi.org/10.18517/ijaseit.8.1.3731

Md Ghazali, N.H. (2016). A Reliability and Validity of an Instrument to Evaluate the School-Based Assessment System: A Pilot Study. International Journal of Evaluation and Research in Education, 5 (2), 148. https://doi.org/10.11591/ijere.v5i2.4533

Mihalache, O.A., Dumitraşcu, L., Nicolau, A.I. and Borda, D. (2020). Food safety knowledge, food shopping attitude and safety kitchen practices among Romanian consumers: A structural modelling approach. Food Control, 120, 107545. https:// doi.org/10.1016/j.foodcont.2020.107545

Mohajan, H.K. (2017). Two Criteria for Good Measurements in Research: Validity and Reliability. Annals of Spiru Haret University, 17(4), 59-82. https://doi.org/10.26458/1746

Mohd Firdaus, S.A., Son, R., Mohhiddin, O., Toh, P.S., and Chai, L.C. (2015). Food court hygiene assessment and food safety knowledge, attitude and practices of food handlers in Putrajaya. International Food Research Journal, 22(5), 1843-1854.

Montshiwa, V.T. and Moroke, N.D. (2014). Assessment of the reliability and validity of student-lecturer evaluation questionnaire: A case of North West University. Mediterranean Journal of Social Sciences, 5(14), 352-364. https://doi.org/10.5901/ mjss.2014.v5n14p352

Moser, D.K., Riegel, B., McKinley, S., Doering, L.V., Meischke, H., Heo, S. and Dracup, K. (2009). The Control Attitudes Scale-Revised: Psychometric evaluation in three groups of patients with cardiac illness. Nursing Research, 58(1), 42-51. https:// doi.org/10.1097/NNR.0b013e3181900ca0

Mullan, B.A., Wong, C., Todd, J., Davis, E. and Kothe, E.J. (2015). Food hygiene knowledge in adolescents and young adults. British Food Journal, 117(1), 5061. https://doi.org/10.1108/BFJ-03-2013-0060

Neff, K.D., and Germer, C.K. (2013). A Pilot Study and Randomized Controlled Trial of the Mindful SelfCompassion Program. Journal of Clinical Psychology, 69(1), 28-44. https://doi.org/10.1002/ jclp.21923

Ng, B.Y., Kankanhalli, A. and Xu, Y. (Calvin). (2009). Studying users' computer security behavior: A health belief perspective. Decision Support Systems, 46(4), 815-825. https://doi.org/10.1016/ j.dss.2008.11.010

Nik Rosmawati, N.H., Wan Muda, W.M., Noor Izani, N.J., Nik Nurain, N.H., and Razlina, A.R. (2016). Effect of food safety training on food handlers' knowledge and practices: A randomized controlled trial. British Food Journal, 118(4), 795-808. https:// doi.org/10.1108/BFJ-08-2015-0294

Nik Rosmawati, N.H, Wan Manan, W.M, Noor Izani, N.J. and Nik Nurain, N.H (2015). Validity and Reliability of Food Safety Knowledge and Practices Questionnaire among Food Handlers. Health and the Environment Journal, 6(1), 11-30.

Odeyemi, O.A., Sani, N.A., Obadina, A.O., Saba, C.K.S., Bamidele, F.A., Abughoush, M. and Aberoumand, A. (2018). Food safety knowledge, attitudes and practices among consumers in developing countries: An international survey. Food Research International, 116, 1386-1390. https:// doi.org/10.1016/j.foodres.2018.10.030

Quaigrain, K. and Arhin, A.K. (2017). Using reliability and item analysis to evaluate a teacher-developed test in educational measurement and evaluation. Cogent Education, 4(1), 1-11. https:// doi.org/10.1080/2331186X.2017.1301013

Rao, C., Prasad, K. H., Sajitha, K., Permi, H. and Shetty, J. (2016). Original Article Item analysis of multiplechoice questions: Assessing an assessment tool in medical students. International Journal of Educational and Psychological Researches, 2(4), 201-204. https://doi.org/10.4103/2395-2296.189670

Reethesh, S.R., Ranjan, P., Arora, C., Kaloiya, G.S., Vikram, N.K., Dwivedi, S.N. and Soneja, M. (2019). Development and validation of a questionnaire assessing knowledge, attitude, and practices about obesity among obese individuals. Indian Journal of Endocrinology and Metabolism, 23(1), 102-110. https://doi.org/10.4103/ijem.IJEM_487_18

Ruby, G.E., Abidin, U.F.U.Z., Lihan, S., Jambari, N.N. and Radu, S. (2019a). Predicting intention on safe food handling among adult consumers: A cross sectional study in Sibu district, Malaysia. Food Control, 106(1), 1-8. https://doi.org/10.1016/ j.foodcont.2019.06.022

Ruby, G.E., Abidin, U.F.U.Z., Lihan, S., Jambari, N.N. and Radu, S. (2019b). A cross sectional study on food safety knowledge among adult consumers. Food Control, 99, 98-105. https://doi.org/10.1016/ j.foodcont.2018.12.045

Ruby, G.E., Abidin, U.F.U.Z., Lihan, S., Jambari, N.N. and Radu, S. (2019c). Self-reported Food Safety Practices Among Adult Consumers in Sibu, Malaysia: A Cross-sectional Study. Food Protection 
Trends, 39(5), 366-376.

Serena, J.M. (2020). Spitting in public places too can spread infections. Retrieved October 4, 2020, from https://www.thehindu.com/news/cities/chennai/ watch-out-spitting-in-public-places-too-can-spreadinfections/article30814578.ece

Singh, A.K., Dudeja, P., Kaushal, N. and Mukherji, S. (2016). Impact of health education intervention on food safety and hygiene of street vendors: A pilot study. Medical Journal Armed Forces India, 72(3), 265-269. https://doi.org/10.1016/j.mjafi.2016.02.008

Squires, J.E., Estabrooks, C.A., Newburn-Cook, C.V. and Gierl, M. (2011). Validation of the conceptual research utilization scale: An application of the standards for educational and psychological testing in healthcare. BMC Health Services Research, 11(1), 107. https://doi.org/10.1186/1472-6963-11-107

Taherdoost, H. (2018). Validity and Reliability of the Research Instrument; How to Test the Validation of a Questionnaire/Survey in a Research. SSRN Electronic Journal, 5(3), 28-36. https:// doi.org/10.2139/ssrn.3205040

Tapsir, R., Nik Pa, N.A. and Zamri, S.N.A.B.S. (2018). Reliability and Validity of the Instrument Measuring Values in Mathematics Classrooms. Malaysian Online Journal of Educational Sciences, 6(2), 37-47.

Ungku Fatimah, U.Z.A., Boo, H.C., Sambasivan, M. and Salleh, R. (2011). Foodservice hygiene factors-The consumer perspective. International Journal of Hospitality Management, 30(1), 38-45. https:// doi.org/10.1016/j.ijhm.2010.04.001

Ursachi, G., Horodnic, I.A. and Zait, A. (2015). How Reliable are Measurement Scales? External Factors with Indirect Influence on Reliability Estimators. Procedia Economics and Finance, 20(15), 679-686. https://doi.org/10.1016/s2212-5671(15)00123-9

Whitehead, A.L., Julious, S.A., Cooper, C.L. and Campbell, M.J. (2015). Estimating the sample size for a pilot randomised trial to minimise the overall trial sample size for the external pilot and main trial for a continuous outcome variable. Statistical Methods in Medical Research, 25(3), 1057-1073. https://doi.org/10.1177/0962280215588241

Woh, P.Y., Thong, K.L., Behnke, J.M., Lewis, J.W. and Mohd Zain, S.N. (2016). Evaluation of basic knowledge on food safety and food handling practices amongst migrant food handlers in Peninsular Malaysia. Food Control, 70, 64-73. https://doi.org/10.1016/j.foodcont.2016.05.033

Zainuddin, W.M., Ariffin, W.N., Mohd-Nazri, S., Sukeri, S., Zawaha, I., Bakar, R.A. and Aziah, D. (2018). development and validation of new knowledge, attitude, belief and practice questionnaire on leptospirosis in Malaysia. BMC Public Health, 18, 1 -12 .

Zulkifly, M., Salleh, M., Hanafiah, M. and Jamaluddin, M. (2013). Assessing Knowledge, Attitude and Practice (KAP) on food safety among food handlers in Universiti Teknologi Mara (UiTM), Shah Alam. In Zainal, A. (Ed.) Hospitality and Tourism, p. 567572. USA: CRC Press. https://doi.org/10.1201/ b16064-115 